\title{
Genetic analysis of early field growth of loblolly pine clones and seedlings from the same full-sib families
}

\author{
Brian S. Baltunis, Dudley A. Huber, Timothy L. White, Barry Goldfarb, and \\ Henry E. Stelzer
}

\begin{abstract}
Field trials established with clones and seedlings from the same families provide an opportunity for comparing full-sib family performance across propagule types. More than 1200 different clones together with over 14000 zygotic seedlings from the same 61 full-sib families of loblolly pine (Pinus taeda L.) were tested on multiple sites across Florida and Georgia. The genetic variance associated with several early growth traits partitioned differently depending on propagule type. Most of the genetic variance associated with growth in the clonal population was additive, while the estimate of dominance in the seedling population was greater than estimates of dominance in the clonal population, based on single-site analyses. Apparently, a lack of randomization of the seedlings prior to field establishment caused full-sib families to appear more different, inflating estimates of dominance genetic variance. Parental and full-sib family ranks were stable regardless of propagule type as indicated by type B genetic correlations. In the clonal population, little genotype $\times$ environment interaction was observed across sites at the parental, family, and clonal levels for all traits. The high genetic correlations between propagule types provide further assurance that selections made through traditional tree-improvement activities for recurrent selection for general combining ability in seedling trials can also be used successfully for breeding families to test in a clonal forestry program.
\end{abstract}

Résumé : Les plantations comparatives établies à l'aide de clones et de semis provenant des mêmes familles permettent de comparer la performance des descendances biparentales à partir des deux types de propagules. Les auteurs ont testés plus de 1200 clones différents ainsi que 14000 semis zygotiques provenant des mêmes 61 descendances biparentales de pin à encens (Pinus taeda L.) dans plusieurs stations en Floride et en Georgie. La variance génétique reliée à plusieurs caractères de croissance juvénile se répartissait différemment selon le type de propagules. La plus grande partie de la variance génétique reliée à la croissance était additive chez la population clonale alors que l'estimation de la dominance était plus grande pour la population de semis que pour la population clonale lorsque les stations étaient analysées séparément. Apparemment, un manque d'aléation des semis avant leur établissement au champ a entraîné des différences plus grandes entre les descendances biparentales, gonflant ainsi les estimations de variance génétique reliée à la dominance. Le rang des parents et celui des descendances biparentales étaient stables peu importe le type de propagules, tel que l'indiquaient les corrélations génétiques de type B. Chez la population clonale, il y avait peu d'interaction entre le génotype et l'environnement dans l'ensemble des stations à l'échelle des parents, des familles et des clones pour tous les caractères. Les fortes corrélations génétiques observées entre les types de propagules fournissaient une assurance additionnelle confirmant que les sélections effectuées par le biais des activités traditionnelles d'amélioration des arbres. basées sur la sélection récurrente en fonction de l'habileté générale à la combinaison à partir de tests de semi, peuvent aussi être utilisées avec succès dans le cas des descendances issues de croisements dirigés pour effectuer des tests dans le cadre d'un programme de foresterie clonale.

[Traduit par la Rédaction]

\section{Introduction}

Loblolly pine (Pinus taeda L.) is the most important commercial tree species in the United States, with over one billion seedlings planted annually (McKeand et al. 2003).
Tree-improvement programs for loblolly pine are now beginning their third generation of breeding and testing (McKeand and Bridgewater 1998) and have relied on recurrent selection for general combining ability for improving a few key traits. Traditional tree-improvement programs using open-

Received 23 January 2006. Accepted 18 July 2006. Published on the NRC Research Press Web site at cjfr.nrc.ca on 11 April 2007.

B.S. Baltunis, 1,2 D.A. Huber, and T.L. White. School of Forest Resources and Conservation, Institute of Food and Agricultural Sciences, University of Florida, Gainesville, FL 32611, USA.

B. Goldfarb. Department of Forestry and Environmental Resources, North Carolina State University, Raleigh, NC 27695, USA.

Henry E. Stelzer. Department of Forestry, University of Missouri-Columbia, Columbia, MO 65211, USA.

${ }^{1}$ Corresponding author (e-mail: brian.baltunis@ensisjv.com).

${ }^{2}$ Present address: Ensis, CSIRO Forestry and Forest Products, P.O. Box E4008, Kingston 2604, A.C.T., Australia. 
pollinated seed orchard seedlings for deployment only capture additive genetic variation. However, nonadditive genetic variation may be an important component of variation in some traits, and additive and nonadditive genetic variation can be captured by deploying full-sib families or clones. Trials established with full-sib seedlings allow the genetic variance to be partitioned into additive and dominance components (Falconer and Mackay 1996). These trials yield ranks not only of parents or individuals for selection but also of full-sib families in order to provide information for making deployment decisions.

Field trials established with clonally replicated progeny allow for further partitioning of the genetic variance into additive, dominance, and epistatic genetic components with greater precision than with zygotic seedling progeny and can provide greater gain for operational deployment than seedling options (Burdon and Shelbourne 1974; Foster and Shaw 1988; Isik et al. 2004). Using current technologies, several forest industries in the southeastern United States are pursuing clonal forestry programs with loblolly pine (Weber and Stelzer 2002). In the initial stages of these clonal forestry programs, forest managers needed assurance that the clonal propagules' growth corresponded to that of seedlings, therefore earlier studies were designed to test whether cuttings grew similarly to seedlings. Based on those results, it is generally accepted that cuttings rooted from juvenile stock plants grow and perform comparably to seedlings. For example, Foster and Shaw (1987) concluded that loblolly pine rooted cuttings should perform comparably to seedlings when the cuttings come from vigorous juvenile stock plants. In addition, McRae et al. (1993) concluded that for loblolly pine there were no significant differences between seedlings and rooted-cutting propagules from common checklots through 5 years of growth. Similar results were obtained by Frampton et al. (2000), who reported no significant differences in the means for height, diameter at breast height, and volume between rooted cuttings and seedlings through 6 years in the field.

Trials established with clones and seedlings from the same families provide an opportunity for comparing full-sib family performance across propagule types. Genetic correlations between propagule types can provide further assurance that selections made through traditional tree-improvement activities for recurrent selection for general combining ability in seedling trials can also be used successfully to test breeding families in a clonal forestry program. Although a number of studies have compared rooted cuttings and seedlings, very few have been designed to estimate the genetic correlation between propagule types for a trait.

Several previous clonal studies have reported deficiencies in mating design and number of parents or families (Frampton and Huber 1995; Paul et al. 1997; Isik et al. 2003). For example, Frampton and Huber (1995) reported that they had low power in partitioning the genetic variance because of the lack of a mating design among the parents of the full-sib crosses in a loblolly pine clonal study. In addition, Frampton and Foster (1993) warned that it may be difficult to interpret the results of studies that only include seedlings and cuttings from a common checklot to be compared with the clonal propagules from select parents and families. In this case, any differences in field performance because of propagule type may be confounded with differences in genetic improvement (Frampton and Foster 1993).

The current study employs a complex genetic structure to increase power in quantifying the genetic variance associated with several early growth traits in loblolly pine. More than 1200 different clones together with zygotic seedlings from the same 61 full-sib families were tested on multiple sites across Florida and Georgia in the southeastern United States. The specific objectives of this study were to $(i)$ estimate the heritability of various growth traits of loblolly pine clones and seedlings, (ii) compare the performance of parents and full-sib families when grown as rooted cuttings and seedlings, and (iii) determine the extent of the genotype $\times$ environment interaction by looking at the genetic correlations for parents, families, and clones across multiple sites.

\section{Materials and methods}

\section{Population}

The parental population consisted of 20 first-generation and 10 second-generation selections, a subset from the Loblolly Pine Lower Gulf Elite Population. Two additional first-generation, slow-growing parents were included to provide some connectedness with a separate study. The parental selections represent the Atlantic Coastal Plain, Florida, and Lower Gulf provenances of loblolly pine (for details see Forest Biology Research Cooperative (FBRC) 2000). Briefly, these 32 loblolly pine parents were mated in a partial diallel design and created 70 full-sib families from which more than 2000 seedling hedges were generated and given unique clonal identifications. On average, each parent was involved in approximately four crosses.

\section{Propagation}

The propagation of the rooted cuttings for the field trials was previously described (Baltunis et al. 2005). Briefly, the seedling hedges were repeatedly sheared to reduce the effects of maturation and increase the number of shoots available for collection. Stem cuttings were collected from seedling hedges from 61 full-sib families, placed randomly in clonal-row plots, and replicated 6 times in each of three rooting trials in a greenhouse in January, April, and June of 2002. At the time of collection, the hedges were 22, 25, and 27 months old from seed, respectively. Cuttings were assessed for rooting 11 weeks after setting (Baltunis et al. 2005). Rooted cuttings were then transplanted into Ray Leach SuperCells ${ }^{\mathrm{TM}}$ (Steuwe and Sons, Corvalis, Oregon) and randomized into their designated field planting order and grown to size. The clonal propagules for a field trial came from a single rooting trial (Table 1).

A single crop of seedlings, on the other hand, was used to produce all the seedlings for the field trials. Loblolly pine seeds from the same full-sib families from which the clones were derived were stratified for about 30 days and then sown in May 2002. The seedlings were grown in family blocks in a different greenhouse than the cuttings. The seedlings were then moved outdoors under shade cloth and kept in their family blocks in an area separate from where the rooted cuttings were growing. The seedlings were not randomized into their designated field order until just prior to planting. 
Table 1. Locations of six field trials, with establishment date and total number of trial trees for each test.

\begin{tabular}{llllll}
\hline Test & Sticking date & Location & Latitude and longitude & Date planted & Total no. of trees in trial \\
\hline A & January 2002 & Worth County, Georgia & $31^{\circ} 44^{\prime} 20^{\prime \prime} \mathrm{N}, 83^{\circ} 55^{\prime} 50^{\prime \prime} \mathrm{W}$ & October 2002 & 9216 \\
B & April 2002 & Morgan County, Georgia & $33^{\circ} 24^{\prime} 55^{\prime \prime} \mathrm{N}, 83^{\circ} 29^{\prime} 45^{\prime \prime} \mathrm{W}$ & November 2002 & 8960 \\
C & April 2002 & Putnam County, Florida & $29^{\circ} 38^{\prime} \mathrm{N}, 81^{\circ} 46^{\prime} \mathrm{W}$ & November 2002 & 8960 \\
D & April 2002 & Nassau County, Florida & $30^{\circ} 45^{\prime} 23^{\prime \prime} \mathrm{N}, 81^{\circ} 54^{\prime} 27^{\prime \prime} \mathrm{W}$ & February 2003 & 8960 \\
E & April 2002 & Randolph County, Georgia & $31^{\circ} 48^{\prime} 03^{\prime \prime} \mathrm{N}, 84^{\circ} 41^{\prime} 30^{\prime \prime} \mathrm{W}$ & December 2002 & 4400 \\
F & June 2002 & Santa Rosa County, Florida & $30^{\circ} 50^{\prime} 05^{\prime \prime} \mathrm{N}, 87^{\circ} 11^{\prime} 57^{\prime \prime} \mathrm{W}$ & April 2003 & 6912 \\
\hline
\end{tabular}

Table 2. Total number of clones, full-sib families, average number of clones per full-sib family, and average number of seedlings per full-sib family established at the six field trials.

\begin{tabular}{|c|c|c|c|c|c|c|c|}
\hline & Test A & Test B & Test $\mathrm{C}$ & Test D & Test E & Test F & Total \\
\hline Total no. of clones & 974 & 941 & 942 & 956 & 868 & 756 & 1212 \\
\hline Total no. of full-sib families & 61 & 61 & 61 & 61 & 61 & $61^{a}$ & 61 \\
\hline Avg. no. of seedlings per full-sib family & 27.9 & 27 & 27 & 27 & 15.2 & 35.1 & 151.2 \\
\hline
\end{tabular}

${ }^{a}$ Only 47 full-sib families are represented in the seedling population of test F.

\section{Field design}

In total, 47408 measurement trees were established at six field trials (tests A-F) across the southeastern United States (Table 1). Three trials each were established in Florida and Georgia (Table 1). An additional field trial was established in Virginia with a subset of the clones but was not included in any of these analyses. There were four replications in each of two cultural treatments (high and low intensity) in each trial except test $\mathrm{E}$, where there was only one cultural treatment and four replications. The goal for the highintensity treatment was to push the trees to their utmost potential by reducing competition and providing a nonlimiting supply of nutrients, while the low-intensity culture provides insights into family and clonal performance under a less optimal cultural regime (FBRC 2000). The two cultural intensities were treated similarly during the first year, and cultural differences were implemented at the beginning of the second growing season.

In total, more than 1200 different clones were planted in field trials (Table 2). However, not all clones were available for planting across the six field trials. Each trial contained 756-974 clones, with approximately 15 clones from each of 61 full-sib families (Table 2). The trials were designed to have four zygotic seedlings from each of the same 61 full-sib families within each replication. However, because of poor germination in some of the families or mortality in the nursery, each full-sib family is represented, on average, by approximately 27 zygotic seedlings per trial (Table 2). Both the rooted cuttings and seedlings were planted in singletree plots utilizing a resolvable alpha incomplete block design (Williams et al. 2002) in which incomplete block size ranged from 10 to 14 trees. The variables measured were 1styear height, 2nd-year height, height increment, and crown width. Crown width was measured in two directions (parallel and perpendicular to the row) at the widest point of the live crown, and the mean of the two measurements was used in all analyses.

\section{Statistical analyses}

All growth variables — 1st-year height, 2nd-year height, height increment, and crown width - were analyzed in ASREML (Gilmour et al. 2002) using a parental model to estimate the genetic variance components associated with these traits. Analyses were conducted for each trial separately and across all six trials for each propagule type. The across-trial analyses assumed a different error variance for each trial. For the clonal population, the following acrosstrial model was used. All random effects were assumed to be normally, identically, and independently distributed (NIID).

$$
\begin{aligned}
& y_{i j k l m n o p}=\mu+T_{i}+C_{j(i)}+R_{k(i j)}+\mathrm{incbk}_{l(i j k)}+\mathrm{gca}_{m} \\
&+ \mathrm{gca}_{n}+\mathrm{sca}_{m n}+\operatorname{clone}_{\mathrm{o}(m n)}+t \times \mathrm{gca}_{i m}+t \\
& \times \mathrm{gca}_{i n}+t \times \mathrm{fam}_{i m n}+t \times \mathrm{clone}_{i \mathrm{o}(m n)}+c \\
& \times \mathrm{gca}_{j(i) m}+c \times \mathrm{gca}_{j(i) n} \\
&+c \times \operatorname{fam}_{j(i) m n}+c \times \operatorname{clone}_{j(i) \mathrm{o}(m n)} \\
&+r \times \operatorname{gca}_{k(i j) m}+r \times \operatorname{gca}_{k(i j) n} \\
&+r \times \mathrm{fam}_{k(i j) m n}+e_{i j k l m n o p}
\end{aligned}
$$

where

$y_{i j k l m n o p}$ is the measured growth trait of the $p$ th ramet of the oth clone within the $m n$th full-sib family in the $l$ th incomplete block within the $k$ th replication of the $j$ th cultural treatment in the $i$ th trial

$\mu$ is the clonal population mean

$T_{i}$ is the fixed effect of trial, $i=1, \ldots, 6$

$C_{j}(i)$ is the fixed effect of culture within trial, $j=1,2$

$R_{k(i j)}$ is the fixed effect of replication, $k=1,2,3,4$

incbk $_{l(i j k)}$ is the random effect of incomplete block associated with each trial $\sim \operatorname{NIID}\left(0, \hat{\sigma}_{\mathrm{INC}_{i}}^{2}\right)$

$\mathrm{gca}_{m}$ and $\mathrm{gca}_{n}$ are the random effects of female $(m)$ and male (n) general combining ability, respectively, $\sim \operatorname{NIID}\left(0, \hat{\sigma}_{\mathrm{GCA}}^{2}\right)$

$\mathrm{sca}_{m n}$ is the random effect of specific combining ability $\sim \operatorname{NIID}\left(0, \hat{\sigma}_{\mathrm{SCA}}^{2}\right)$

clone $_{\mathrm{o}(m n)}$ is the random effect of clone within full-sib family $\sim \operatorname{NIID}\left(0, \hat{\sigma}_{\text {CLONE }}^{2}\right)$

$t \times \mathrm{gca}_{i m}$ and $t \times \mathrm{gca}_{\text {in }}$ are the random effects of trial $\times$ female general combining ability and trial $\times$ male gen- 
eral combining ability interactions, respectively, $\sim \operatorname{NIID}\left(0, \hat{\sigma}_{\text {TEST } \times G C A}^{2}\right)$

$t \times$ fam $_{\text {imn }}$ is the random effect of trial $\times$ full-sib family interaction $\sim \operatorname{NIID}\left(0, \hat{\sigma}_{\mathrm{TEST} \times \mathrm{FAM}}^{2}\right)$

$t \times$ clone $_{i \mathrm{o}(m n)}$ is the random effect of trial $\times$ clone within full-sib family interaction $\sim \operatorname{NIID}\left(0, \hat{\sigma}_{\text {TEST } \times \text { CLONE }}^{2}\right)$

$c \times \mathrm{gca}_{j(i) m}$ and $c \times \mathrm{gca}_{j(i) n}$ are the random effects of culture within trial $\times$ female general combining ability and culture within trial $\times$ male general combining ability, respectively, $\sim \operatorname{NIID}\left(0, \hat{\sigma}_{\mathrm{C} \times \mathrm{GCA}}^{2}\right)$

$c \times \operatorname{fam}_{j(i) m n}$ is the random effect of culture within trial $\times$ full-sib family $\sim \operatorname{NIID}\left(0, \hat{\sigma}_{\mathrm{C} \times \mathrm{FAM}}^{2}\right)$

$c \times$ clone $_{j(i) \mathrm{o}(m n)}$ is the random effect of culture within trial $\times$ clone within full-sib family interaction $\sim \operatorname{NIID}(0$, $\hat{\sigma}_{\mathrm{C} \times \mathrm{CLONE}}^{2}$ )

$r \times \mathrm{gca}_{k(i j) m}$ and $r \times \mathrm{gca}_{k(i j) n}$ are the random effects of replication $\times$ female general combining ability and replication $\times$ male general combining ability, respectively, $\sim \operatorname{NIID}\left(0, \hat{\sigma}_{\mathrm{REP} \times \mathrm{GCA}}^{2}\right)$

$r \times$ fam $_{k(i j) m n}$ is the random effect of replication $\times$ full-sib family $\sim \operatorname{NIID}\left(0, \hat{\sigma}_{\mathrm{REP} \times \mathrm{FAM}}^{2}\right)$

$e_{i j k l m n o p}$ is the random error associated with each trial $\sim \operatorname{NIID}\left(0, \hat{\sigma}_{\text {ERROR }}^{2}\right)$

The single-site model for the clonal population is identical except that the effect of trial and the interaction effects between trial and other model factors are removed.

Incomplete blocks contained clones and seedlings, and therefore, when only the seedling observations were considered, too few observations were left in each incomplete block to be of significance. As a consequence, all traits were analyzed for the seedling population assuming a randomized complete block design. Both single-trial analyses and an across-trial analysis were performed, again assuming heterogeneous errors across sites.

$$
\begin{aligned}
z_{i j k l m n} & =\mu+T_{i}+C_{j(i)}+R_{k(i j)}+\mathrm{gca}_{l}+\mathrm{gca}_{m}+\mathrm{sca}_{l m} \\
& +t \times \mathrm{gca}_{i l}+t \times \mathrm{gca}_{i m}+t \times \mathrm{fam}_{i l m}+c \\
& \times \mathrm{gca}_{j(i) l}+c \times \mathrm{gca}_{j(i) m}+c \times \mathrm{fam}_{j(i) l m}+r \\
& \times \mathrm{gca}_{k(i j) l}+r \times \mathrm{gca}_{k(i j) m}+r \times \mathrm{fam}_{k(i j) l m}+e_{i j k l m n}
\end{aligned}
$$

where $z_{i j k l m n}$ is the measured growth trait of the $n$th seedling from the $l m$ th full-sib family in the $k$ th replication of the $j$ th cultural treatment in the $i$ th trial, $\mu$ is the seedling population mean, and the other variables are defined as above (just with the subscripts adjusted appropriately).

Genetic parameters were estimated and standard errors were calculated according to Foster and Shaw (1988) using the variance components from the appropriate model.

$$
\hat{V}_{\mathrm{A}}=4 \hat{\sigma}_{\mathrm{GCA}}^{2}=V_{\mathrm{A}}+\frac{1}{4} V_{\mathrm{AA}}+\frac{1}{16} V_{\mathrm{AAA}} \cdots
$$

is the estimate of additive genetic variance.

$$
\hat{V}_{\mathrm{D}}=4 \hat{\sigma}_{\mathrm{SCA}}^{2}=V_{\mathrm{D}}+\frac{1}{2} V_{\mathrm{AA}}+\frac{1}{2} V_{\mathrm{AD}}+\frac{1}{4} V_{\mathrm{DD}} \cdots
$$

is the estimate of dominance genetic variance.

$$
\begin{aligned}
\hat{V}_{\mathrm{I}}=\hat{\sigma}_{\mathrm{CLONE}}^{2}-2 \hat{\sigma}_{\mathrm{GCA}}^{2}-3 \hat{\sigma}_{\mathrm{SCA}}^{2}= & \frac{1}{4} \\
& V_{\mathrm{AA}} \\
& +\frac{1}{2} V_{\mathrm{AD}}+\frac{3}{4} V_{\mathrm{DD}} \cdots
\end{aligned}
$$

is the estimate of epistatic genetic variance for the clonal population.

$$
\hat{V}_{\mathrm{G}_{\mathrm{C}}}=2 \hat{\sigma}_{\mathrm{GCA}}^{2}+\hat{\sigma}_{\mathrm{SCA}}^{2}+\hat{\sigma}_{\mathrm{CLONE}}^{2}
$$

is the estimate of total genetic variance for the clonal population.

[7]

$$
\hat{V}_{\mathrm{G}_{\mathrm{S}}}=4 \hat{\sigma}_{\mathrm{GCA}}^{2}+4 \hat{\sigma}_{\mathrm{SCA}}^{2}
$$

is the estimate of total genetic variance for the seedling population (assuming no epistasis).

$$
\begin{aligned}
\hat{V}_{\mathrm{P}_{\mathrm{c}}}= & 2 \hat{\sigma}_{\mathrm{GCA}}^{2}+\hat{\sigma}_{\mathrm{SCA}}^{2}+\hat{\sigma}_{\mathrm{CLONE}}^{2}+2 \hat{\sigma}_{\mathrm{TEST} \times \mathrm{GCA}}^{2} \\
& +\hat{\sigma}_{\mathrm{TEST} \times \mathrm{FAM}}^{2}+\hat{\sigma}_{\mathrm{TEST} \times \mathrm{CLONE}}^{2}+2 \hat{\sigma}_{\mathrm{C} \times \mathrm{CGA}}^{2} \\
& +\hat{\sigma}_{\mathrm{C} \times \mathrm{FAM}}^{2}+\hat{\sigma}_{\mathrm{C} \times \mathrm{CLONE}}^{2}+2 \hat{\sigma}_{\mathrm{REP} \times \mathrm{GCA}}^{2} \\
& +\hat{\sigma}_{\mathrm{REP} \times \mathrm{FAM}}^{2}+\frac{\sum_{i=1}^{6} \hat{\sigma}_{\mathrm{ERROR}_{i}}^{2}}{6}
\end{aligned}
$$

is the estimated phenotypic variance for the across-trial model for the clonal population.

$$
\begin{array}{r}
\hat{V}_{\mathrm{P}_{\mathrm{S}}}=2 \hat{\sigma}_{\mathrm{GCA}}^{2}+\hat{\sigma}_{\mathrm{SCA}}^{2}+2 \hat{\sigma}_{\mathrm{TEST} \times \mathrm{GCA}}^{2}+\hat{\sigma}_{\mathrm{TEST} \times \mathrm{FAM}}^{2} \\
+2 \hat{\sigma}_{\mathrm{C} \times \mathrm{GCA}}^{2}+\hat{\sigma}_{\mathrm{C} \times \mathrm{FAM}}^{2}+2 \hat{\sigma}_{\mathrm{REP} \times \mathrm{GCA}}^{2} \\
+\hat{\sigma}_{\mathrm{REP} \times \mathrm{FAM}}^{2}+\frac{\sum_{i=1}^{6} \hat{\sigma}_{\mathrm{ERROR}_{i}}^{2}}{6}
\end{array}
$$

is the estimated phenotypic variance for the across-trial model for the seedling population.

Individual-tree narrow-sense heritability $\left(\hat{h}^{2}\right)$ and broadsense heritability $\left(\hat{H}^{2}\right)$ were derived using the estimated variance components for all the growth traits and each propagule type at each site and across sites. Standard errors were calculated using Taylor's series expansion (Kendall and Stuart 1963; Namkoong 1979; Huber et al. 1992; Dieters 1994). The following heritability formulae were used for the clonal data:

$$
\hat{h}^{2}=\frac{\hat{V}_{\mathrm{A}_{\mathrm{C}}}}{\hat{V}_{\mathrm{P}_{\mathrm{C}}}} \approx \frac{4 \hat{\sigma}_{\mathrm{GCA}}^{2}}{\hat{V}_{\mathrm{P}_{\mathrm{C}}}}
$$

is the across-trial estimate of $\hat{h}^{2}$ for the clonal population, where $\hat{V}_{\mathrm{P}_{\mathrm{C}}}$ is from [8].

$$
\hat{H}^{2}=\frac{\hat{V}_{\mathrm{G}_{\mathrm{C}}}}{\hat{V}_{\mathrm{P}_{\mathrm{C}}}} \approx \frac{2 \hat{\sigma}_{\mathrm{GCA}}^{2}+\hat{\sigma}_{\mathrm{SCA}}^{2}+\hat{\sigma}_{\mathrm{CLONE}}^{2}}{\hat{V}_{\mathrm{P}_{\mathrm{C}}}}
$$

is the across-trial estimate of $\hat{H}^{2}$ for the clonal population, where $\hat{V}_{\mathrm{P}_{\mathrm{C}}}$ is from [8].

Heritability estimates were also obtained for the seedling data for each trial and across trials. 


$$
\hat{h}^{2}=\frac{\hat{V}_{\mathrm{A}_{\mathrm{s}}}}{\hat{V}_{\mathrm{P}_{\mathrm{S}}}} \approx \frac{4 \hat{\sigma}_{\mathrm{GCA}}^{2}}{\hat{V}_{\mathrm{P}_{\mathrm{S}}}}
$$

is the across-trial estimate of $\hat{h}^{2}$ for the seedling population, where $\hat{V}_{\mathrm{P}_{\mathrm{S}}}$ is from [9].

$$
\hat{H}^{2}=\frac{\hat{V}_{\mathrm{G}_{\mathrm{S}}}}{\hat{V}_{\mathrm{P}_{\mathrm{S}}}} \approx \frac{4 \hat{\sigma}_{\mathrm{GCA}}^{2}+4 \hat{\sigma}_{\mathrm{SCA}}^{2}}{\hat{V}_{\mathrm{P}_{\mathrm{S}}}}
$$

is the across-trial estimate of $\hat{H}^{2}$ for the seedling population, where $\hat{V}_{\mathrm{P}_{\mathrm{s}}}$ is from [9].

The various growth variables at each site were also analyzed with a bivariate mixed model with the growth trait of the clones and seedlings as two dependent variables. Type B genetic correlations for general combining ability $\left(\hat{\mathrm{B}}_{\mathrm{p} \text { propGCA }}\right)$ and full-sib family value $\left(\hat{r}_{\mathrm{B}}{ }_{\text {propFs }}\right)$ between rooted cuttings and seedlings were estimated in order to compare parental and full-sib family performance between propagule types. The genetic correlation between propagule types for additive effects, for example, gives us an indication of whether parental ranks depend upon whether their progeny are grown as cuttings or seedlings, while a type B genetic correlation at the full-sib family level measures the performance of full-sib families across propagule types.

$$
\hat{r}_{\mathrm{B}_{\text {propGCA }}}=\frac{\hat{\sigma}_{\text {gca }_{\text {clone }}, \text { gca }_{\text {seedling }}}}{\sqrt{\left(\hat{\sigma}_{\text {gca }_{\text {clone }}}^{2}\right)\left(\hat{\sigma}_{\text {gca }_{\text {sedlling }}}^{2}\right)}}
$$

is the type B genetic correlation of additive effects between propagule types using genetic variance component estimates

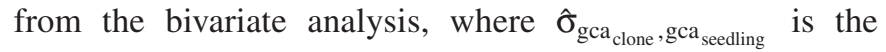
covariance between general combining ability effects in the clonal and seedling populations, and $\hat{\sigma}_{\text {gca clone }}^{2}$ and $\hat{\sigma}_{\text {gca }_{\text {sedling }}}^{2}$ are the estimated genetic variances for general combining ability in the clonal and seedling populations, respectively.

$$
\hat{r}_{\mathrm{B}_{\text {propFs }}}=\frac{2 \hat{\sigma}_{\text {gca }_{\text {clone }}, \mathrm{gca}_{\text {seedling }}}+\hat{\sigma}_{\text {sca }_{\text {clone }}, \mathrm{sca}_{\text {sedlling }}}}{\sqrt{\left(2 \hat{\sigma}_{\text {gca }_{\text {clone }}}^{2}+\hat{\sigma}_{\text {sca }_{\text {clone }}}^{2}\right)\left(2 \hat{\sigma}_{\text {gca }_{\text {seedling }}}^{2}+\hat{\sigma}_{\text {sca }_{\text {sedling }}}^{2}\right)}}
$$

is the type B genetic correlation of full-sib family values between propagule types using genetic variance component estimates from the bivariate analysis, where $\hat{\sigma}_{\text {sca }}$ clone, sca $_{\text {sedling }}$ is the covariance between specific combining ability effects in the clonal and seedling populations, and $\hat{\sigma}_{\text {sca cone }^{2}}^{2}$ and $\hat{\sigma}_{\text {sca }_{\text {seedling }}}^{2}$ are the estimated genetic variances for ${ }^{\text {specific }}$ combining ability in the clonal and seedling populations, respectively.

The extent of the genotype $x$ environment interaction was investigated by analyzing data across trials for each propagule type using the variance components from the appropriate model. Type B genetic correlations were calculated for additive effects, full-sib family, and the total genetic or clonal value across the trials (Yamada 1962; Burdon 1977). Standard errors of type B genetic correlations were calculated using Taylor's series expansion method.

$$
\hat{r}_{\mathrm{B}_{\mathrm{g} \times \mathrm{GCA}}}=\frac{\hat{\sigma}_{\mathrm{GCA}}^{2}}{\hat{\sigma}_{\mathrm{GCA}}^{2}+\hat{\sigma}_{\mathrm{TEST} \times \mathrm{GCA}}^{2}}
$$

is the type B genetic correlation for additive effects across trials.

$$
\hat{r}_{\mathrm{B}_{\mathrm{g} \times \mathrm{eFs}}}=\frac{2 \hat{\sigma}_{\mathrm{GCA}}^{2}+\hat{\sigma}_{\mathrm{SCA}}^{2}}{2 \hat{\sigma}_{\mathrm{GCA}}^{2}+2 \hat{\sigma}_{\mathrm{TEST} \times \mathrm{GCA}}^{2}+\hat{\sigma}_{\mathrm{SCA}}^{2}+\hat{\sigma}_{\mathrm{TEST} \times \mathrm{FAM}}^{2}}
$$

is the type B genetic correlation for full-sib families across trials.

$$
\hat{\mathrm{B}}_{\mathrm{g} \times \mathrm{eCLONE}}=\frac{2 \hat{\sigma}_{\mathrm{GCA}}^{2}+\hat{\sigma}_{\mathrm{SCA}}^{2}+\hat{\sigma}_{\mathrm{CLONE}}^{2}}{2 \hat{\sigma}_{\mathrm{GCA}}^{2}+2 \hat{\sigma}_{\mathrm{TEST} \times \mathrm{GCA}}^{2}+\hat{\sigma}_{\mathrm{SCA}}^{2}+\hat{\sigma}_{\mathrm{TEST} \times \mathrm{FAM}}^{2}+\hat{\sigma}_{\mathrm{CLONE}}^{2}+\hat{\sigma}_{\mathrm{TEST} \times \mathrm{CLONE}}^{2}}
$$

is the type B genetic correlation for total genetic or clonal value across trials for the clonal population.

Values of $\hat{r}_{\mathrm{B}_{\mathrm{g} \times \mathrm{eGCA}}}$ range from 0 to 1 , and a value near 1 indicates little genotype $x$ environment interaction and that the parents ranked the same across the trials, while a low $\hat{r}_{\mathrm{B}}$ value (near zero) indicates that parental ranks were nơt stable across the sites and hence, a genotype $\times$ environment interaction exists. A high $\hat{r}_{\mathrm{B}_{\mathrm{g} \times \mathrm{eFS}}}$ value indicates that full-sib families ranked similarly across the sites, while a high $\hat{r}_{\mathrm{B} \times \text { CLONE }}$ value indicates that the ranking of total genetic values of the clones was stable across the trials.

\section{Results and discussion}

\section{Overall growth of clones and seedlings}

Rates of survival of both clonal and zygotic propagules were high across all of the field trials. Survival of the rooted cuttings ranged from $91.7 \%$ to $98.3 \%$ at the six field trials, while seedling survival ranged from $86.5 \%$ to $97.4 \%$. At the time of planting, seedlings were generally taller than rooted cuttings, and this trend has continued through year 2 (Table 3). For example, after the first and second growing seasons seedlings were, on average, 11 and $10 \mathrm{~cm}$ taller than rooted cuttings, respectively. It has been suggested that 
Table 3. Mean 1st-year height, 2nd-year height, height increment, and crown width by propagule type for the six field trials.

\begin{tabular}{|c|c|c|c|c|}
\hline & $\begin{array}{l}\text { 1st-year } \\
\text { height (m) }\end{array}$ & $\begin{array}{l}\text { 2nd-year } \\
\text { height (m) }\end{array}$ & $\begin{array}{l}\text { Height } \\
\text { increment }(\mathrm{m})\end{array}$ & $\begin{array}{l}\text { Crown } \\
\text { width (m) }\end{array}$ \\
\hline \multicolumn{5}{|l|}{ Test A } \\
\hline Clones & 1.0 & 2.1 & 1.2 & 0.9 \\
\hline Seedlings & 1.1 & 2.3 & 1.2 & 1.0 \\
\hline \multicolumn{5}{|l|}{ Test B } \\
\hline Clones & 0.8 & 1.8 & 1.0 & 0.9 \\
\hline Seedlings & 0.9 & 1.8 & 1.0 & 0.9 \\
\hline \multicolumn{5}{|l|}{ Test C } \\
\hline Clones & 1.0 & 2.1 & 1.1 & 1.2 \\
\hline Seedlings & 1.1 & 2.3 & 1.2 & 1.3 \\
\hline \multicolumn{5}{|l|}{ Test D } \\
\hline Clones & 0.7 & 2.0 & 1.3 & 1.0 \\
\hline Seedlings & 0.8 & 2.1 & 1.3 & 1.1 \\
\hline \multicolumn{5}{|l|}{ Test E } \\
\hline Clones & 1.2 & 3.3 & 2.0 & 2.0 \\
\hline Seedlings & 1.3 & 3.2 & 1.9 & 2.0 \\
\hline \multicolumn{5}{|l|}{ Test F } \\
\hline Clones & 0.5 & 1.7 & 1.3 & 1.1 \\
\hline Seedlings & 0.6 & 1.8 & 1.3 & 1.1 \\
\hline
\end{tabular}

Note: Although means are expressed in metres, analyses were conducted using traits measured in centimetres.

propagule size differences at the time of planting may create difficulties in the analysis and interpretation of subsequent growth (Frampton and Foster 1993). However, these differences in initial propagule size may not be a problem in the current study because height increments were very similar in the two propagule types, with site means ranging from 1.0 to 2.0 and from 1.0 to $1.9 \mathrm{~m}$ for rooted cuttings and seedlings, respectively (Table 3 ).

The initial and 1st-year treatments were the same within a site during trial establishment, and there were no cultural differences between propagule types for 1st-year height. There were some differences in mean height resulting from different effects of cultural intensity during the second growing season at some of the sites. However, these effects were more a function of scale. Although the overall means of the growth variables differed by cultural treatment, the ranks of parents, families, or clones were not affected. Type B genetic correlations exceeded 0.85 , indicating little cultural treatment $\times$ genetic effect interaction, therefore cultural effects are ignored for the purposes of this study. This implies that the ranks of parents, families, and clones were robust across multiple management regimes through age 2 .

\section{Genetic components of variance}

All of the early growth traits demonstrated genetic variance (Fig. 1, Table 4). However, the genetic variance partitioned differently for the two propagule types. In all cases the estimate of additive genetic variance was greater for the clones than the seedlings. For example, the estimate of additive genetic variance for the clonal material was 4.7, 3.3, 2.9 , and 2 times greater than the additive genetic variance for seedlings for 1st-year height, 2nd-year height, height increment, and crown width, respectively (Table 4).

Based on single-trial analyses, most of the genetic variance associated with all of the growth variables in the clonal pop- ulation was additive, while in the seedling population the trend was towards nonadditive genetic variance (Fig. 1). For example, at test $\mathrm{D}$ all of the genetic variance associated with 2nd-year height of clones was additive, while for the seedlings it was dominance (Fig. 1). When all of the data were analyzed together, the estimates of dominance genetic variance were approximately equivalent for the two propagule types (Table 4 ), suggesting a large trial $\times$ dominance interaction for the seedlings. Epistasis was negative for all growth variables. Isik et al. (2003) reported similar trends in the partitioning of the genetic variance for loblolly pine clones and seedlings, including negative epistasis estimates for height, diameter, and volume through age 6 . They also reported that the additive genetic variance for growth traits was always greater for clones than the estimate for seedlings, while dominance genetic variance was greater in the seedling population (Isik et al. 2003).

Genetic causes are not the only source of similarity among relatives. $\mathrm{C}$ effects are nongenetic factors that are common to members of a group of relatives such as a clone or family (Lerner 1958). These nongenetic factors can lead to upwardly biased estimates of total genetic and nonadditive genetic components of variance when clonal data are analyzed (Libby and Jund 1962). C effects are often assumed to be negligible when estimating epistatic variance (Foster and Shaw 1988). If C effects are present, the total genetic variance associated with clones will be overestimated (Libby and Jund 1962). Significant C effects are likely to occur in traits that are measured soon after propagation, but apparently lessen for traits measured later (Libby and Jund 1962). In the current experiment, if $\mathrm{C}$ effects exist, then estimates of epistatic genetic variance will be confounded with $\mathrm{C}$ effects because ramets of a clone came from a single non-replicated hedge. However, the estimates for epistasis were negative for all of the growth traits (Table 4), which suggests that interlocus 
Fig. 1. Proportions of additive and nonadditive genetic variance components for clones and seedlings across the six field trials, where narrow-sense heritability $\left(\hat{h}^{2}\right)$ is the proportion of additive genetic variance and broad-sense heritability $\left(\hat{H}^{2}\right)$ is the proportion of additive and nonadditive genetic variance. (a) 1st-year height. (b) 2nd-year height. $(c)$ Height increment. $(d)$ Crown width. Standard error bars for $\hat{H}^{2}$ estimates are included.
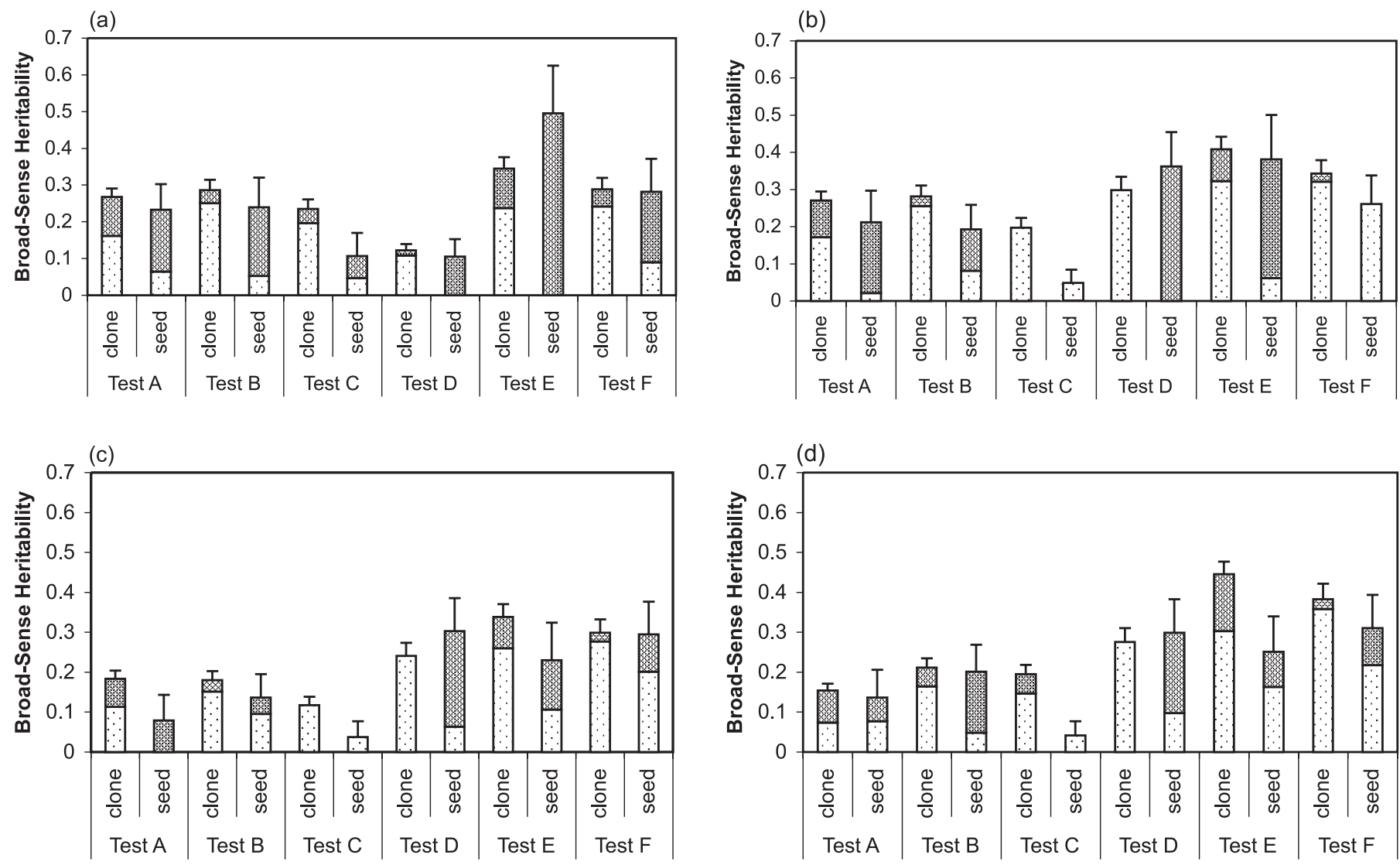

图nonadditive Dadditive

interactions are not an important source of genetic variance for early growth traits, and that $\mathrm{C}$ effects may not be a major contributing factor. Further, estimates of additive genetic variance and dominance should be free of confounding $\mathrm{C}$ effects in the current experiment, since randomization of clones occurred at all stages including hedge establishment, propagation, and growth prior to and after trial establishment.

As Falconer and Mackay (1996) point out, relatives of all sorts may resemble one another because of sharing a common environment. The variance attributed to a common environment occurs more frequently and makes a greater contribution to the covariance of full-sibs than to the covariance of any other sort of relatives (Falconer and Mackay 1996). When a common environment effect exists, the differences between means for families become greater than when these nongenetic factors are not present. In the case of full-sib families, this will lead to biased or inflated estimates of dominance genetic variance.

The results seen in the current experiment for obtaining dominance genetic variance estimates in the seedling population appear to be caused by a partitioning problem in that estimates of the variance due to dominance are inflated at the expense of additive effects (Fig. 1). Seeds are often sown and seedlings grown in full-sib family blocks in the greenhouse or nursery for progeny testing or other field testing.
To eliminate the common environment effect at the family level, seedlings within a full-sib family should be randomized over the environment in which they are being grown and tested. Although rooted cuttings were randomized at all stages of propagation, the seedlings were in fact grown in full-sib blocks, and a common environment effect has apparently carried over to the field through age- 2 measurements.

\section{Heritability estimates}

In the current study, 1st-year height, 2nd-year height, height increment, and crown width were all heritable. The $\hat{h}^{2}$ estimates were always greater for clones than for seedlings for all of the traits (Fig. 1, Table 4). Generally, $\hat{h}^{2}$ estimates of total height increased from age 1 to age 2 for both clones and seedlings (Fig. 1, Table 4). The $\hat{h}^{2}$ estimates for total height increased from 0.16 at age 1 to 0.22 at age 2 for the clones but increased from 0.04 to 0.07 for the seedling population (Table 4). Yet the differences in heritability estimates between the propagule types may be related to $\mathrm{C}$ effects. If $\mathrm{C}$ effects are present, then $\hat{H}^{2}$ estimates for the clonal population may be inflated. However, $\hat{h}^{2}$ estimates from the clonal population may not be upwardly biased, since clones within full-sib families were randomized in the hedge orchard and throughout the study, thus reducing spurious $\mathrm{C}$ effects at the parental and full-sib family levels. 
Table 4. Genetic parameter estimates for 1st-year height, 2nd-year height, height increment, and crown width by propagule type across all six trials.

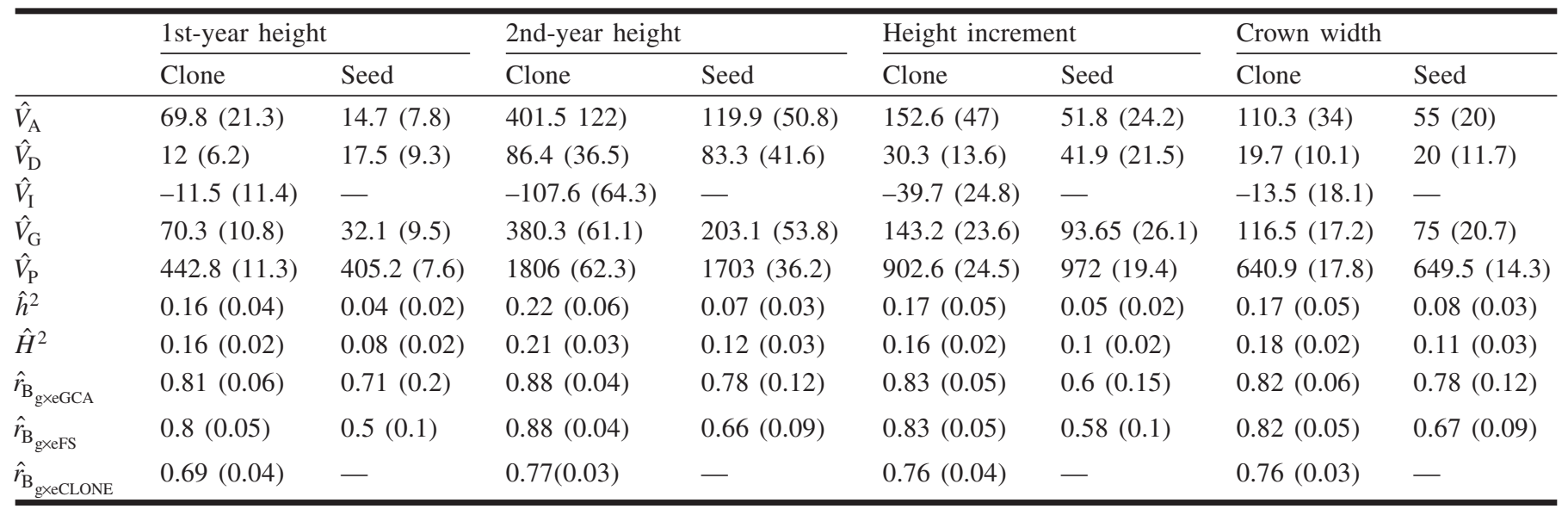

Note: Values in parentheses are standard errors.

Heritability estimates have been reported for several loblolly pine seedling and clonal populations. In a study reported by Isik et al. (2003), $\hat{h}^{2}$ for volume at age 6 was 0.3 for clones but 0.06 for seedlings. In another loblolly pine clonal trial, heritability estimates for total height growth through age 5 for two factorials were similar to the values reported here (Paul et al. 1997). They reported $\hat{h}^{2}$ for 1 st- and 2 nd-year height to be 0.08 and 0.17 , respectively (mean of two factorials). Unfortunately, they did not include seedlings in their study. Analogous results have been reported in Eucalyptus globulus Labill. for heritability estimates for diameter for both clones and seedlings in that $\hat{h}^{2}$ was always greater for the clonal population than for the seedling population (Costa e Silva et al. 2004).

The $\hat{H}^{2}$ estimates for the various growth traits were always larger for the clonal material than for the seedlings, except for 1st-year height at test $\mathrm{E}$ and all four variables at test $\mathrm{D}$ (Fig. 1). The $\hat{H}^{2}$ estimates from the across-trial models were always greater for the clones than for the seedlings (Table 4), which can be attributed to a higher estimate of the total genetic variance for the clonal population. However, the $\hat{H}^{2}$ estimates for the clonal and seedling populations may not be statistically different, based on $95 \%$ confidence intervals. Because of the negative estimates of epistasis in the clonal population, the $\hat{H}^{2}$ estimates were equivalent to the $\hat{h}^{2}$ estimates for all traits. The $\hat{H}^{2}$ estimates for seedlings had higher standard errors associated with them (Fig. 1).

\section{Type B genetic correlations between propagule types}

To further compare the clonal rooted cuttings and zygotic seedlings, type B genetic correlations for general combining ability and full-sib family value between propagule types were estimated. For all growth traits measured, the type B genetic correlation between propagule types for additive effects was high, with values exceeding 0.72 (Table 5). For example, $\hat{r}_{\mathrm{B}}$ propGCA ranged from 0.93 to 0.99 for 1 st-year height but from 0.72 to 0.99 for height increment (Table 5). These high genetic correlations imply that parental ranks for early growth traits are stable regardless of whether their progeny are being tested as zygotic seedlings or rooted cuttings (Fig. 2a).
Type B genetic correlations for additive effects between propagule types observed in the current study were consistent with the expected correlations reported by Borralho and Kanowski (1995). In a simulation study comparing the performance of clones and seedlings from the same half-sib family, Borralho and Kanowski (1995) reported that the expected correlations between propagule types exceeded 0.8 when more than 100 seedlings or propagules were tested. Additionally, in a field study comparing rooted cuttings and seedlings from four half-sib families of loblolly pine, Foster and Shaw (1987) reported that family rank correlations between propagule types were positive and significant for 1st-year height (0.52), 3rd-year height (0.66), and 6th-year height (0.70).

Full-sib families also ranked relatively similarly regardless of propagule type at most of the sites (Table 5, Fig. 2b). For example, type B genetic correlations at the full-sib family level ranged from 0.64 to 0.89 for 2nd-year height. However, $\hat{r}_{\mathrm{B}}$ ropFs varied more from site to site for 1st-year height and height increment. Estimates of type B genetic correlations for full-sib families across propagules were low for some of the traits at some of the sites. However, these low $\hat{r}_{\mathrm{B} p r o p S}$ estimates may be more a function of the inflated estimates of dominance in the seedling population (Fig. 1). Type B genetic correlations for full-sib families across propagule types were less than additive genetic correlations, implying that there were more rank changes for full-sib families. Generally, the results observed here are in accordance with those reported by Frampton et al. (2000) in that full-sib families or parental trees selected on the basis of seedling genetic trials should also perform well as rooted cuttings.

\section{Genotype $x$ environment interaction}

The stability of parents and full-sib families across sites was compared between the clonal and seedling populations (Table 4). The type B genetic correlation for additive effects across sites was always greater for the clones, although these estimates were moderately high for both populations. For example, $\hat{r}_{\mathrm{B} \times \mathrm{eGCA}}$ for 2nd-year height was 0.88 and 0.78 for the clonal and seedling populations, respectively (Table 4). Full-sib families also ranked comparably across sites for the 
Table 5. Genetic correlations between propagule types for 1st-year height, 2nd-year height, height increment, and crown width at the parental $\left(\hat{r}_{\mathrm{B}_{\text {propGCA }}}\right)$ and full-sib family $\left(\hat{r}_{\mathrm{B}_{\text {propFS }}}\right)$ levels.

\begin{tabular}{|c|c|c|c|c|c|c|c|c|}
\hline \multirow[b]{2}{*}{ Test } & \multicolumn{2}{|c|}{ 1st-year height } & \multicolumn{2}{|c|}{ 2nd-year height } & \multicolumn{2}{|c|}{ Height increment } & \multicolumn{2}{|c|}{ Crown width } \\
\hline & $\hat{r}_{\mathrm{B}_{\text {propGCA }}}$ & $\hat{r}_{\mathrm{B}_{\text {propFS }}}$ & $\hat{r}_{\mathrm{B}_{\text {propGCA }}}$ & $\hat{r}_{\mathrm{B}_{\text {propFS }}}$ & $\hat{r}_{\mathrm{B}_{\text {propGCA }}}$ & $\hat{r}_{\mathrm{B}_{\text {propFS }}}$ & $\hat{r}_{\mathrm{B}_{\text {propGCA }}}$ & $\hat{r}_{\mathrm{B}_{\text {propFS }}}$ \\
\hline $\mathrm{A}$ & 0.99 & 0.62 & 0.99 & 0.65 & 0.99 & 0.38 & 0.86 & 0.86 \\
\hline B & 0.99 & 0.74 & 0.99 & 0.86 & 0.99 & 0.99 & 0.99 & 0.81 \\
\hline $\mathrm{C}$ & 0.93 & 0.74 & 0.99 & 0.75 & 0.99 & 0.99 & 0.99 & 0.97 \\
\hline $\mathrm{D}$ & 0.93 & 0.44 & 0.99 & 0.64 & 0.99 & 0.92 & 0.93 & 0.92 \\
\hline $\mathrm{E}$ & 0.99 & 0.55 & 0.89 & 0.71 & 0.72 & 0.77 & 0.99 & 0.69 \\
\hline $\mathrm{F}$ & 0.95 & 0.49 & 0.96 & 0.89 & 0.95 & 0.83 & 0.99 & 0.83 \\
\hline
\end{tabular}

Fig. 2. Rank-rank plots showing type B genetic correlations between clones and seedlings from test B based on predicted parental ranks $(a)$ and predicted full-sib family ranks $(b)$ for 2nd-year height, where predicted full-sib values are equal to the sum of the predicted general combining ability for each of the two parents plus the predicted specific combining ability of the cross.

(a)
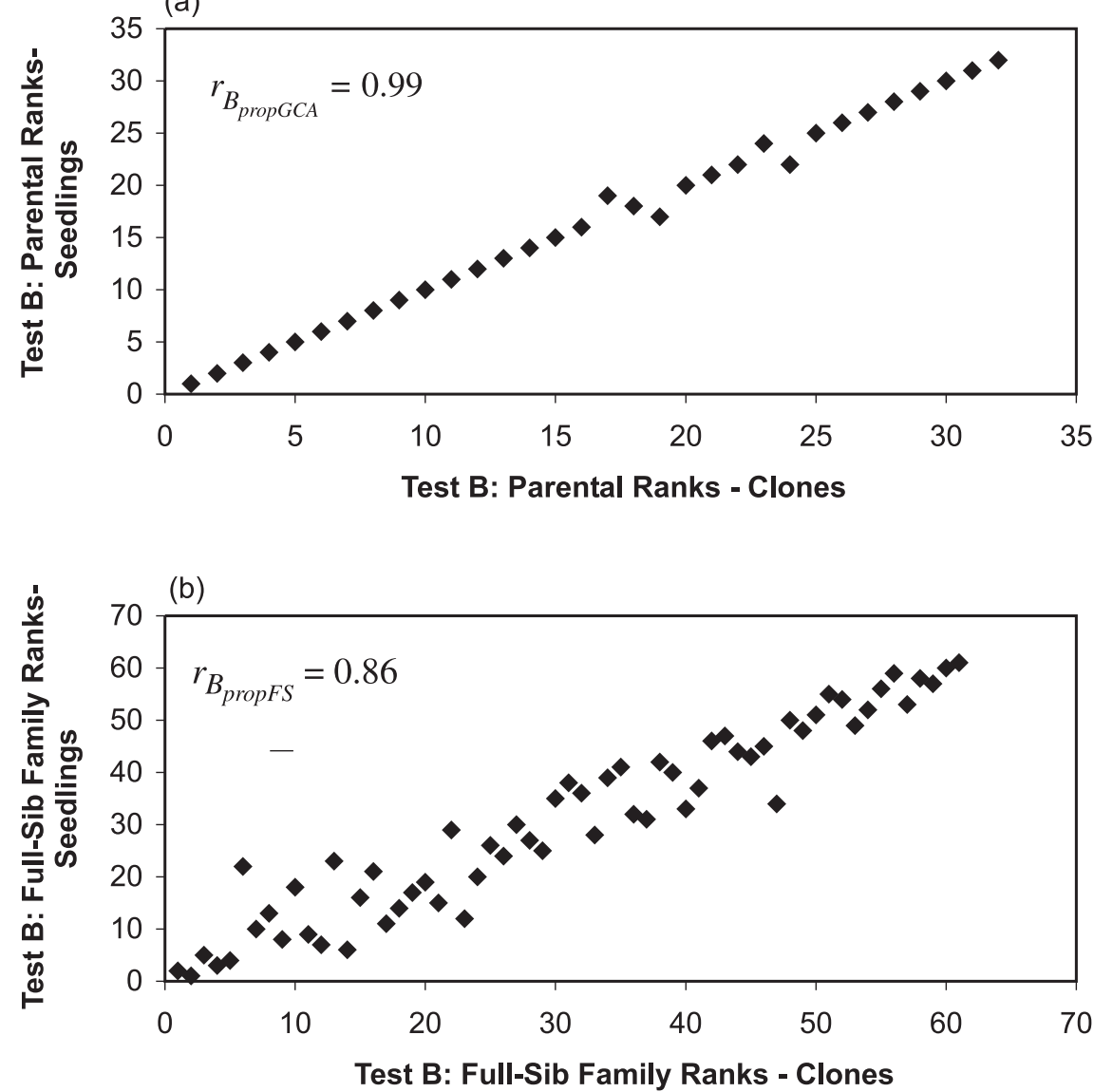

clonal population, with $\hat{r}_{\mathrm{B} \times \mathrm{eFS}}$ values exceeding 0.8 for all of the early growth traits (Table 4). These across-site genetic correlations were estimated with more precision using clonal replicates, as evidenced by lower standard errors for the estimates from the clonal population.

An additional genotype $\times$ environment interaction between trial and total genetic value can be estimated using clonal trials. The total genetic values for the clones were fairly stable when all of the data were considered from all sites, indicating that a good clone at one site is good at all the sites (Table 4). However, based on analyses from pairs of trials (data not shown), there appears to be a propagation effect relating to the season when the cuttings were rooted. For example, the worst genetic correlations were observed between the trial established with rooted cuttings from the winter setting and any of the other trials, while the best genetic correlations were obtained from the field trials that included rooted cuttings originating from the spring setting. Similar results were also observed with rooting ability in this same population in that poor genetic correlations were observed between rooting ability in winter and spring (Baltunis et al. 2005).

\section{Conclusion}

Based on the results of the current study, several conclu- 
sions can be drawn. First, clonally replicated seedling trials of loblolly pine provide genetic information with greater precision than those using zygotic seedlings. Second, parental and full-sib family ranks were generally stable regardless of propagule type as indicated by type B genetic correlations. This implies that parental and full-sib family ranks based on existing seedling progeny trials could be used to select parents and families that perform well when they are deployed as rooted cuttings. However, type B genetic correlations for full-sib families across propagule types were less than additive genetic correlations, implying that there were more rank changes for full-sib families than for parents. In addition, low estimates of type B genetic correlations for full-sib families across propagules were observed for some of the traits. On the other hand, these low estimates may be more a function of the inflated estimates of dominance in the seedling population. Third, little genotype $\times$ environment interaction was observed across sites at the parental, family, and clonal levels for all traits in the clonal population. However, there appears to be a carry-over effect relating to the season in which the cuttings were rooted for the clonal material. As these results are only based on growth through age 2, caution is needed in extrapolating the results through rotation age. As these trials age, a genotype $\times$ environment interaction may develop, especially since the population contains Florida-source loblolly pine, which has been shown to be more interactive with the environment. On the other hand, if these trends continue, these results suggest that in clonal forestry programs using loblolly pine, clones that perform well across many different environments could be selected. Finally, randomization is essential at all stages of testing when estimating genetic parameters. The lack of randomization for the seedling population apparently resulted in a problem with partitioning of the genetic variance, causing full-sib families to appear more different and inflating estimates of dominance genetic variance. $\mathrm{C}$ effects, including nongenetic effects associated with a common nursery environment, apparently lessen over time, therefore we expect the upward biases observed in estimates of dominance in the seedling population to diminish over time.

\section{Acknowledgements}

The authors thank the members of the Forest Biology Research Cooperative (FBRC) for supporting this research. The authors extend their appreciation to the FBRC members who installed a study site: Weyerhaeuser, Plum Creek, Rayonier, MeadWestvaco, and the International Paper Company. Special thanks go to the University of Georgia for also establishing a study site. The authors also thank the Associate Editor and the two anonymous reviewers for their relevant comments on an earlier draft.

\section{References}

Baltunis, B.S., Huber, D.A., White, T.L., Goldfarb, B., and Stelzer, H.E. 2005. Genetic effects of rooting loblolly pine stem cuttings from a partial diallel mating design. Can. J. For. Res. 35: 10981108 .
Borralho, N.M.G., and Kanowski, P.J. 1995. Correspondence of performance between genetically related clones and seedlings. Can. J. For. Res. 25: 500-506.

Burdon, R.D. 1977. Genetic correlation as a concept for studying genotype-environment interaction in forest tree breeding. Silvae Genet. 26: 168-175.

Burdon, R.D., and Shelbourne, C.J.A. 1974. The use of vegetative propagules for obtaining genetic information. N.Z. J. For. Sci. 4: 418-425.

Costa e Silva, J., Borralho, N.M.G., and Potts, B.M. 2004. Additive and non-additive genetic parameters from clonally replicated and seedling progenies of Eucalyptus globulus. Theor. Appl. Genet. 108: 1113-1119.

Dieters, M.J. 1994. Inheritance of volume and rust resistance in slash pine. Ph.D. dissertation, University of Florida, Gainesville, Fla.

Falconer, D.S., and Mackay, T.F.C. 1996. Introduction to quantitative genetics. 4th ed. Longman Group Ltd., Harlow, Essex, UK.

Forest Biology Research Cooperative. 2000. Study B: clonal biology and performance of elite genotypes of loblolly and slash pine. FBRC Rep. 13, Forest Biology Research Cooperative, University of Florida, Gainesville, Fla.

Foster, G.S., and Shaw, D.V. 1987. A tree improvement program to develop clones of loblolly pine for reforestation. In Proceedings of 19th Southern Forest Tree Improvement Conference, College Station, Tex., 16-18 June 1987. pp. 17-21.

Foster, G.S., and Shaw, D.V. 1988. Using clonal replicates to explore genetic variation in a perennial plant species. Theor. Appl. Genet. 76: 788-794.

Frampton, L.J., Jr., and Foster, G.S. 1993. Field testing vegetative propagules. In Clonal forestry. I. Genetics and biotechnology. Edited by M.H. Ahuja and W.J. Libby. Springer-Verlag, Berlin, Germany. pp. 110-134.

Frampton, L.J., Jr., and Huber, D.A. 1995. Clonal variation in fouryear-old loblolly pine in coastal North Carolina. In Proceedings of 23rd Southern Forest Tree Improvement Conference, Asheville, N.C., 20-22 June 1995. pp. 254-264.

Frampton, L.J., Jr., Li, B., and Goldfarb, B. 2000. Early field growth of loblolly pine rooted cuttings and seedlings. South. J. Appl. For. 23: 108-115.

Gilmour, A.R., Gogel, B.J., Cullis, B.R., Welham, S.J., and Thompson, R. 2002. ASReml user guide. Release 1.0. VSN International Ltd., Hemel Hempstead, UK.

Huber, D.A., White, T.L., and Hodge, G.R. 1992. The efficiency of half-sib, half-diallel and circular mating designs in the estimation of genetic parameters in forestry: a simulation. For. Sci. 38: 757-776.

Isik, F., Li, B., and Frampton, L.J. 2003. Additive, dominance, and epistatic variance estimates from a replicated clonal test of loblolly pine. For. Sci. 49: 77-88.

Isik, F., Li, B., Frampton, J., and Goldfarb, B. 2004. Efficiency of seedlings and rooted cuttings for testing and selection in Pinus taeda. For. Sci. 50: 44-53.

Kendall, M.G., and Stuart, A. 1963. The advanced theory of statistics. Vol. 1. Hafner, New York.

Lerner, I.M. 1958. The genetic basis of selection. John Wiley \& Sons, Inc., New York.

Libby, W.J., and Jund, E. 1962. Variance associated with cloning. Heredity, 17: 533-540.

McKeand, S., Mullin, T., Byram, T., and White, T. 2003. Deployment of genetically improved loblolly and slash pines in the south. J. For. 101: 32-37. 
McKeand, S.E., and Bridgewater, F.W. 1998. A strategy for the third breeding cycle of loblolly pine in the south-eastern U.S. Silvae Genet. 47: 223-234.

McRae, J.B., Stelzer, H.E., Foster, G.S., and Caldwell, T. 1993. Genetic results from a tree improvement program to develop clones of loblolly pine for reforestation. In Proceedings of 22nd Southern Forest Tree Improvement Conference, Atlanta, Ga., 14-17 June 1993. pp. 424-433.

Namkoong, G. 1979. Introduction to quantitative genetics in forestry. USDA For. Serv. Tech. Bull. 1588.

Paul, A.D., Foster, G.S., Caldwell, T., and McRae, J. 1997. Trends in genetic and environmental parameters for height, diameter, and volume in a multilocation clonal study with loblolly pine. For. Sci. 43: 87-98.
Weber, J., and Stelzer, H. 2002. Operational rooted cuttings in southern pines. In National Proceedings: Forest and Conservation Nursery Associations - 1999, 2000, and 2001. Proceedings RMRS-P-24. Technical coordinators R.K. Dumroese, L.E. Riley, and T.D. Landis. USDA Forest Service, Rocky Mountain Research Station, Ogden, Utah. pp. 91-92.

Williams, E.R., Matheson, A.C., and Harwood, C.E. 2002. Experimental design and analysis for tree improvement. 2nd ed. CSIRO Publishing, Collingwood, Victoria, Australia.

Yamada, Y. 1962. Genotype by environment interaction and genetic correlation of the same trait under different environments. Jpn. J. Genet. 37: 498-509. 
Copyright of Canadian Journal of Forest Research is the property of NRC Research Press and its content may not be copied or emailed to multiple sites or posted to a listserv without the copyright holder's express written permission. However, users may print, download, or email articles for individual use. 